\title{
Rate of Recurrence of Non-Small Cell Lung Cancer in Patients Treated with Percutaneous Ablation
}

\author{
Narottam S. Regmi ${ }^{1}$, Brett L. Heber ${ }^{2}$, James W. Klena ${ }^{3}$ \\ ${ }^{1}$ The Department of Internal Medicine, University of Pittsburgh Medical Center Northwest, Seneca, PA, USA \\ ${ }^{2}$ Department of Biology, Juniata College, Huntingdon, PA, USA \\ ${ }^{3}$ Thoracic Surgery Service, University of Pittsburgh Medical Center Northwest, Seneca, PA, USA \\ Email: drnarottam@gmail.com, brettheber@yahoo.com, jwklena@yahoo.com
}

Received 15 September 2014; revised 28 October 2014; accepted 10 November 2014

Copyright (C) 2014 by authors and Scientific Research Publishing Inc.

This work is licensed under the Creative Commons Attribution International License (CC BY).

http://creativecommons.org/licenses/by/4.0/

(c) (i) Open Access

\begin{abstract}
Background: Percutaneous ablation therapy as a treatment for non-small cell lung cancer (NSCLC) has been increasingly utilized. There is little data on long term efficacy. Because of this we reviewed the rate of recurrence of all ablation procedures done at our institution for the last 6 years. Methods: A total of 36 patients underwent 43 percutaneous procedures from July 2008 until January 2014 at our institution. There were 9 patients treated with radiofrequency ablation (RFA) and 27 treated withmicrowave ablation (MWA) for Stage I NSCLC. Each patient was reviewed to determine if there was a recurrence, the time to recurrence and the characteristics of the original cancer possibly predisposing the procedure to failure. Results: There were 8 recurrences in 9 patients undergoing RFA occurring at a median time of 842 days (range 425 - 1568) after their procedure. MWA was utilized in 27 patients for 34 procedures with 11 patients experiencing recurrences at a median time of 487 days (range 168 - 845). The median follow up time for the RFA patients was 1631 days (4.46 years) and for the MWA patients 751 days (2.06 years). Of the RFA recurrences, 5 involved systemic spread of their cancer and 3 were limited to site recurrences only. Of the MWA recurrences, 5 involved systemic spread of their cancer, 2 had chest wall recurrences and 4 were limited to site recurrences only.
\end{abstract}

\section{Keywords}

Ablative Therapies, Lung Cancer, Surgery

\section{Introduction}

Percutaneous ablation techniques including radiofrequency ablation (RFA), microwave ablation (MWA), cryoab-

How to cite this paper: Regmi, N.S., Heber, B.L. and Klena, J.W. (2014) Rate of Recurrence of Non-Small Cell Lung Cancer in Patients Treated with Percutaneous Ablation. Advances in Lung Cancer, 3, 75-81.

http://dx.doi.org/10.4236/alc.2014.34011 
lation and now, irreversible electroporation (IRE) have all been described as modalities with various efficacies at treating non-small cell lung cancer [1]. The use of these modalities for the treatment of lung cancer is being done with increasing frequency [2]. Despite the increased utilization of the percutaneous modalities surgical resection remains the best chance of cure for a patient with an early stage non-small cell lung cancer [3]. Surgical resection is frequently not feasible in patients diagnosed with early non-small cell lung cancer however due to significant comorbidities or patient refusal to undergo surgical resection. In patients denied lobectomy or sublobar resection percutaneous ablation therapy has emerged as an alternative [4].

Radiofrequency ablation has been used for the last decade as an alternative treatment for patients considered too high a surgical risk for lung resection while microwave ablation has been in use for the last several years [5]. Radiofrequency ablation was first utilized at our institution for poor surgical candidates with non-small cell lung cancer in 2008. Microwave ablation supplanted RFA as the percutaneous ablation modality of choice at our institution in 2010 because of its theoretical benefits with respect to heat deposition and tumor lysis in the in vivo lung [1]. Since 2008 over 60 percutaneous ablation procedures for lung cancer have been done at our institution. This paper describes the results of 36 of those patients who presented with clinical Stage 1 non-small cell lung cancer screened, treated and followed post-operatively by a single surgeon at a single institution. Each patient's medical record was reviewed for the presence and time of recurrence, the outcome when a recurrence occurred, and aspects of the original tumor treated that possibly predisposed the patient to recurrence.

\section{Patients and Methods}

\subsection{Patients}

The study was approved by the Institutional Review Board of UPMC Northwest. All of the patients treated in the study were treated and followed at UPMC Northwest between 2008 and 2014 by a single surgeon (JWK). Each of the patients was presented at the institution's multi-specialty tumor board prior to treatment. The patients underwent their pre-operative work up by the thoracic surgery service and were not felt to be candidates for surgical resection due to poor pulmonary function and, or significant comorbidities as defined by the Charlson comorbidity index [6], or patient refusal to undergo an operation. Pre-operative work up consisted of a history and physical, computed tomography (CT), image guided biopsy of the lung nodule and positron emission tomography (PET) to assess the possibility of the presence of metastatic disease prior to undergoing treatment. Patients with any evidence of metastatic disease by CT or PET underwent further work up to pathologically confirm the presence of metastatic disease. Only patients considered having clinical Stage IA (T1a and T1b, N0, M0) NSCLC were included in the study.

\subsection{Methods}

Image guided RFA or MWA using CT guidance was performed with both an interventional radiologist and a thoracic surgeon (JWK) present for the procedure. RFA was used early in the series (2008-2010). Both the Cool-tip ${ }^{\mathrm{TM}}$ RFA system (Valleylab, Boulder, CO) and the RITA ${ }^{\mathrm{TM}}$ system (RITA Medical Systems, Inc, Mountainview CA) were used. An ablation goal of $60^{\circ} \mathrm{C}$ and a $0.5-1 \mathrm{~cm}$ rim of ablation in normal lung parenchyma were the RFA endpoints of treatment. MWA ablation supplanted RFA in 2010 because of the theoretical benefits of its energy dispersal characteristics in lung tissue [1]. All MWA were performed with the Evident ${ }^{\mathrm{TM}}$ system (Covidien, Tyco Healthcare Group, Mansfield, MA). MWA antennae used either a 2.0 or $3.7 \mathrm{~cm}$ active tip emitting microwaves at $915 \mathrm{MHz}$ with an output power of $45 \mathrm{~W}$ for 10 minutes in each case. The antenna size and the need for multiple antennae were chosen based on the CT dimensions of the nodule to be treated with the desired goal of achieving a $0.5-1 \mathrm{~cm}$ rim of normal parenchyma ablated with the cancer [7].

Following ablation patients were followed by the thoracic surgery service at scheduled intervals with clinical exams and appropriate radiological studies. In general, patients underwent surveillance with CT scans at 6 weeks, 3 months, 9 months and 6 month intervals post ablation. Tumor response was evaluated with respect to the Modified Response Evaluation Criteria in Solid Tumors (RECIST) criterion [8]. Patients failing to demonstrate a complete response or a continued partial response by serial CT scans received more aggressive work up including the addition of PET scanning to determine metabolic activity or repeat biopsy of the previously ablated lung cancer. 


\subsection{Analysis}

The medical records of all patients treated with percutaneous ablation at our institution between 2008 and January 2014 were retrospectively reviewed and the patients who experienced recurrence of their lung cancer were reviewed. The site of recurrence, the time to recurrence as evidenced by the first radiological test suggesting it, and the respective outcomes were determined. Additionally, in those patients who experienced a recurrence, their initial presentation findings were reviewed to determine if there were any parameters identifiable predisposing them to recurrence.

\section{Results}

Radiofrequency ablation was utilized in 9 patients. 8 of the 9 patients experienced cancer recurrence (Table 1). The median time until recurrence was 842 days with a range of 425 days to 1,568 days (Figure 1). Of the 8 recurrences 3 had site recurrences only, with 2 undergoing re-ablation and 1 undergoing a sublobar resection. All of these patients continue to be disease free following re-treatment. 3 patients failed without evidence of recurrent disease at the treated site but with significant nodal spread. 1 of these patients succumbed to cancer while 2 remain alive on maintenance adjuvant therapy. 1 patient experienced widely disseminated metastatic disease and succumbed to cancer while 1 patient was found to have a malignant pleural effusion and remains alive on maintenance chemotherapy. A single patient did not experience a cancer recurrence but died from benign pulmonary disease over 5 years after her ablation.

Microwave ablation was utilized in 27 patients for 34 total procedures. 11 of these patients have experienced recurrences (Table 2). The median time until recurrence was 487 days with a range of 165 - 845 days (Figure 2). The follow up interval for the MWA patients is not as mature as the RFA interval due to the transition to MWA during the treatment period. 9 of the recurrences were site recurrences with 4 patients undergoing re-ablation all of whom remain disease free at the present time. 2 patients who experienced site recurrences underwent re-ablation and subsequently developed progressive disease; 1 developed ipsilateral hilar disease and ultimately succumbed to cancer during chemotherapy while the other developed widely metastatic disease and died with palliative chemotherapy. 2 patients presented post-ablation with widely metastatic disease and remain alive on adjuvant therapy. 2 patients, both of whom had peripheral pleural based nodules at their initial ablation, have had chest wall recurrences treated with subsequent external beam radiation. 6 patients treated with MWA were lost to follow up.

After review of both the RFA and MWA results it was felt that further statistical analysis of the patient populations would be of limited value due to the preponderance of recurrence in both groups of patients. Review of all of the patients revealed that all of the originally ablated nodules were no larger than $3 \mathrm{~cm}$ in the greatest dimension with the majority $<2 \mathrm{~cm}$. Additionally, each of the patients underwent pre-treatment PET evaluation and was without evidence of the presence of metastatic disease at the time of their initial ablation procedure. All patients reviewed were thus clinical Stage IA biopsy proven non-small cell lung cancer patients.

\section{Comment}

The American Cancer Society estimates that in 2014 there will be over 220,000 new cases of lung cancer in the United States with over 159,000 cancer deaths. The same report also estimates that greater than two thirds of the patients newly diagnosed will be older than age 65 [9]. It has also been estimated that only $15 \%$ of patients diagnosed with Stage I or II NSCLC meet the physiological criteria for parenchymal resection [10] [11]. The aging of the population in the United States has been well documented; it is estimated that by 2030 the elderly population of the United States will reach 70 million people [12]. It has been demonstrated that CT screening for lung cancer has the potential to detect early stage lung cancers effectively [13]. The combination of the aging population in the U.S. with the increased use of CT scanning is likely to result in more patients with early stage lung cancers that are marginal candidates for surgical resection.

The National Cancer Institute's Surveillance, Epidemiology, and End Results (SEER) registry has previously found survival results for early stage NSCLC to be as high as $75 \%$ at 8 years for patients treated by surgical resection [13]. Conversely the survival results for patients with early stage NSCLC who do not undergo any treatment were found to be, at best, $13 \%$ by the same registry data [14]. Additionally, review of patients with untreated Stage I NSCLC from the California Cancer Registry has previously found that the median survival for patients not undergoing any treatment is 13 months [15]. 
Table 1. Original tumor characteristics, site of recurrence and time from ablation to recurrence in patients treated with Radiofrequency Ablation.

\begin{tabular}{cccc}
\hline Patient Demographics & Nodule Characteristics & Site of Recurrence & Time to Recurrence (days) \\
\hline 60 Years Old Male & $19 \mathrm{~mm}$ LUL Peripheral & N3; Left Supraclavicular Lymph Nodes & 892; Cancer Mortality \\
81 Years Old & $16 \mathrm{~mm}$ LLL Peripheral & M1b; Bilateral Adrenals and Pelvis & 755; Cancer Mortality \\
68 Years Old Female & $15 \mathrm{~mm}$ LUL Peripheral & Site Recurrence & 1568; Re-ablated \\
82 Years Old Male & $13 \mathrm{~mm}$ RUL Peripheral & Site Recurrence with N1, N2 and M1b Disease & 792; Cancer Mortality \\
76 Years Old Female & $19 \mathrm{~mm}$ RLL Peripheral & M1a; Right Pleura & 1435; Chemotherapy \\
68 Years Old Female & $10 \mathrm{~mm}$ LUL Peripheral & Site Recurrence & 425; Re-ablated \\
83 Years Old Male & $16 \mathrm{~mm}$ LUL Peripheral & Site Recurrence & 1120; Segmentectomy \\
64 Years Old Female & $19 \mathrm{~mm}$ LUL Peripheral & N2; AP Zone Nodes &
\end{tabular}

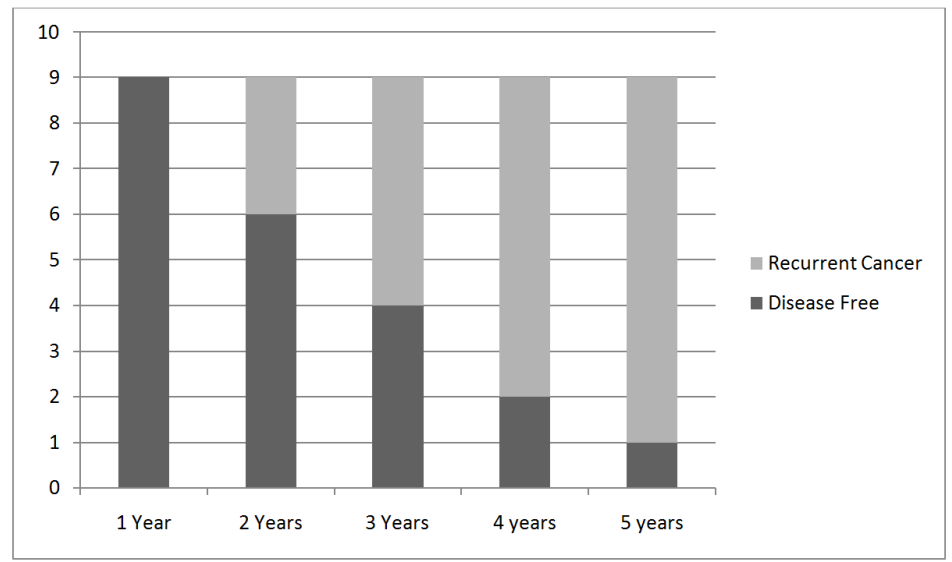

Figure 1. Disease free and recurrent cancer patients from the time of their initial RFA.

Table 2. Original tumor characteristics, site of recurrence and time from ablation to recurrence in patients treated with Microwave Ablation.

\begin{tabular}{|c|c|c|c|}
\hline Patient Demographics & Nodule Characteristics & Site of Recurrence & Time to Recurrence (days) \\
\hline 48 Years Old Male & 16 mm LUL Perihilar & Site Recurrence & 439; Re-ablated \\
\hline 71 Years Old Male & 18 mm RUL Peripheral Abutted Chest Wall & Chest Wall & $\begin{array}{c}\text { 569; Chemotherapy \& External } \\
\text { Beam Radiation }\end{array}$ \\
\hline 69 Years Old Female & 8 mm LUL Peripheral & Site Recurrence & 492; Re-ablated \\
\hline \multirow[t]{2}{*}{78 Years Old Female } & 17 mm RUL Peripheral & Site Recurrence (first) & 368; Re-ablated \\
\hline & & Hepatic Metastatic disease & 440; Cancer Mortality \\
\hline \multirow[t]{3}{*}{81 Years Old Male } & 21 mm RUL Peripheral & Site Recurrence & 845; Re-ablated \\
\hline & 17 mm LLL Peripheral & Site Recurrence (first) & 248; Re-ablated \\
\hline & & Site \& N1 Recurrence & 313; Cancer Mortality \\
\hline 64 Years Old Female & 20 mm RLL Abutted Chest Wall & Site \& Chest Wall & $\begin{array}{c}\text { 168; Chemotherapy \& External } \\
\text { Beam Radiation }\end{array}$ \\
\hline 63 Years Old Male & 28 mm LUL Peripheral & Site \& N1 Recurrence & 296; Chemotherapy \\
\hline 88 Years Old Male & 13mm LUL Mid-lobar & Site Recurrence & 530; Re-ablated \\
\hline 80 Years Old Female & 16 mm LUL Mid-lobar & M1a \& N2 Recurrence & 350; Chemotherapy \\
\hline 84 Years Old Male & 14 mm RUL Peripheral & M1; Widespread & 487; Chemotherapy \\
\hline 70 Years Old Male & 19mm RLL Mid-lobar & Site Recurrence & 669; Chemotherapy \\
\hline
\end{tabular}




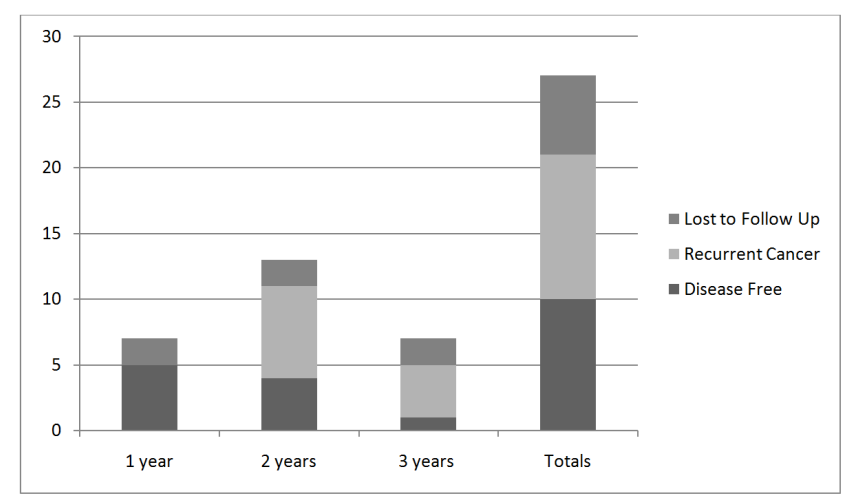

Figure 2. Disease free, recurrent cancer and patients lost to follow up from the time of their initial MWA.

Surgical resection, including lobectomy, anatomic segmentectomy and wedge resection, for the treatment of early stage NSCLC remains the most effective treatment to optimize both survival and freedom from recurrence [16]. The ideal treatment for patients who are not candidates for surgical resection remains to be delineated. Several modalities exist including ablation therapies (RFA, MWA, cryoablation and possibly IRE) and stereotactic ablative radiotherapy (SBRT). All of these modalities appear to be inferior to surgical resection but superior to standard external beam radiation therapy [17]. This paper reviews the results of RFA and MWA at a single institution over a 6-year period. Survival rates for early stage NSCLC treated with RFA have been reported to be as high as $55.7 \%$ at 5 years [5] and as high as $61 \%$ with MWA at 3 years [18].

Our results reflect similar cancer survival results with an overall rate in the RFA group of 66\% (6/9) and 93\% (27/29) in the MWA group. The recurrence rate however is much higher with a rate of $89 \%$ (8/9) and 41\% (11/ 27) respectively. Although the majority of the recurrences were at the ablation site a significant number represented disease progression: 44\% (4/9) for the RFA group and 45\% (5/11) for the MWA group with subsequent need for adjuvant therapy and the high probability that these patients will eventually succumb to their malignancy. The median follow-up periods for the RFA and MWA patients in this series were 4.46 and 2.06 years respectively.

All of the patients in this series were followed prospectively by a single surgeon at a single institution during their presentation, workup, treatment and follow-up. This is the strength of the study. Although the data reflects a retrospective analysis of their outcomes they were meticulously followed after undergoing their ablation. Each ablation was performed with both an interventional radiologist and thoracic surgeon present minimizing the probability of poor technique in the performance of the procedure. The results indicate that RFA and MWA rarely render a patient free of cancer but their performance extends the overall survival of patients with NSCLC. The results also indicate that RFA and MWA can be performed safely for NSCLC and that close follow-up is required for patients undergoing either of the procedures.

Percutaneous ablation procedures, like SBRT, risk under staging patients due to the lack of histological lymph node evaluation [17]. It has been reported previously that for clinical Stage I NSCLC the risk of nodal metastases may be as high as $26 \%$ [19]. This appears to have been true in 5 of the 9 RFA recurrences in our series and 5 of 11 of the MWA patients with recurrent cancer. Only 3 of these 10 patients had clinical evidence of their recurrences within 1 year of their ablation however. It is therefore unclear whether their recurrences occurred from disease that was occult on their pre-procedural radiological work-up or due to persistent site disease that eventually disseminated. Only 3 of these patients had concomitant evidence of persistent disease at the site when their metastatic disease was identified. It is interesting to note that the median time to recurrence was 842 days for the RFA group and 487 days for the MWA group.

The optimum method for follow-up for patients undergoing ablation for NSCLC remains to be elucidated. It has been previously reported that factors predictive of tumor progression for MWA in the treatment of NSCLC include irregular shape of the tumor and an energy application of less than $26.7 \mathrm{~J} / \mathrm{mm}^{3}$ to the tumor [7]. Cavitation of the treated tumor after ablation has also been reported as a positive prognostic sign [18]. It has also been reported that early changes in tumor size as represented by the RECIST criteria have little impact on survival [8]. Our series suggests that energy application and the presence of cavitation are poor surrogates for a histologically 
negative margin and lymph nodes. Meticulous follow-up reveals a high level of recurrence despite energy application rates greater than $1,900 \mathrm{~J} / \mathrm{mm}^{3}$ (45 watts for 10 minutes in tumors with a maximum volume of 14.1 $\mathrm{mm}^{3}$ ) and the presence of cavitation on follow-up CT scans which was present in greater than $50 \%$ of our patients with recurrence demonstrated.

Radiofrequency and microwave ablation are safe techniques in the treatment of Stage I NSCLC. When compared to a median survival of 13 months in untreated patients with similar tumors [15] it appears that they extend survival. Patients should be advised however that cancer recurrence is likely even at a relatively remote date from their treatment. Consideration for surgical resection should be made in all but the most medically unfit patients. Long term, meticulous follow-up is required in the surveillance of patients undergoing percutaneous ablation for non-small cell lung cancer to optimize their survival.

\section{References}

[1] Alexander, E.S. and Dupuy, D.E. (2013) Lung Cancer Ablation: Technologies and Techniques. Seminars in Interventional Radiology, 30, 141-150. http://dx.doi.org/10.1055/s-0033-1342955

[2] Zhu, J.C., Yan, T.D. and Morris, D.L. (2008) A Systemic Review of Radiofrequency Ablation for Lung Tumors. Annals of Surgical Oncology, 15, 1765-1774. http://dx.doi.org/10.1245/s10434-008-9848-7

[3] Yamamoto, K., Ohsumi, A., Kojima, F., Imanishi, N., Matsuoka, K., Ueda, M. and Miyamoto, Y. (2010) Long Term Survival after Video-Assisted Thoracic Surgery Lobectomy for Primary Lung Cancer. Annals of Thoracic Surgery, 89, 353-359. http://dx.doi.org/10.1016/j.athoracsur.2009.10.034

[4] Pennathur, A., Abbas, G., Gooding, W.E., Schuchert, M.J., Gilbert, S., Christie, N.A., et al. (2009) Image-Guided Radiofrequency Ablation of Lung Neoplasm in 100 Consecutive Patients by a Thoracic Surgery Service. Annals of Thoracic Surgery, 88, 1601-1608. http://dx.doi.org/10.1016/j.athoracsur.2009.05.012

[5] De Baere, T., Farouil, G. and Deschamps, F. (2013) Lung Cancer Ablation: What Is the Evidence? Seminars in Interventional Radiology, 30, 151-156. http://dx.doi.org/10.1055/s-0033-1342956

[6] Charlson, M.E., Pompei, P., Ales, K.L. and MacKenzie, C.R. (1987) A New Method of Classifying Prognostic Comorbidity in Longitudinal Studies. Development and Validation. Journal of Chronic Diseases, 40, 373-383. http://dx.doi.org/10.1016/0021-9681(87)90171-8

[7] Vogl, T.J., Worst, T.S., Naguib, N.N., Ackerman, H., Gruber-Rouh, T. and Nour-Eldin, N.A. (2013) Factors Influencing Local Tumor Control in Patients with Neoplastic Pulmonary Nodules Treated with Microwave Ablation: A Risk-Factor Analysis. American Journal of Roentgenology, 200, 665-672. http://dx.doi.org/10.2214/AJR.12.8721

[8] Birchard, K.R., Hoang, J.K., Herndon Jr., J.E. and Patz Jr., E.F. (2009) Early Changes in Tumor Size in Patients Treated for Advanced Stage Nonsmall Cell Lung Cancer Do Not Correlate with Survival. Cancer, 115, 581-586. http://dx.doi.org/10.1002/cncr.24060

[9] American Cancer Society. Cancer Facts and Figures 2014. http://www.cancer.org/cancer/lungcancer-non-smallcell/detailedguide/non-small-cell-lung-cancer-key-statistics

[10] Baisi, A., De Simone, M., Raveglia, F. and Cioffi, U. (2012) Thermal Ablation in the Treatment of Lung Cancer: Present and Future. European Journal of Cardio-Thoracic Surgery, 43, 683-686.

[11] Greene, F.L., Page, D.L., Fleming, I.D., et al. (2002) AJCC Cancer Staging Manual 6th Edition, Springer, New York, 107-181.

[12] A Profile of Older Americans: 2002. (2002-2003) Administration on Aging, Washington DC.

[13] Henschke, C.I., Yankelevitz, D.F., Libby, D.M., et al. (2006) Survival of Patients with Stage I Lung Cancer Detected on CT Screening. New England Journal of Medicine, 355, 1763-1771. http://dx.doi.org/10.1056/NEJMoa060476

[14] Henschke, C.I., Wisnivesky, J.P., Yankelevitz, D.F. and Miettinen, O.S. (2003) Small Stage I Cancers of the Lung: Genuineness and Curability. Lung Cancer, 39, 327-330. http://dx.doi.org/10.1016/S0169-5002(02)00503-2

[15] Raz, D.J., Zell, J.A., Ou, S.H., Gandara, D.R., Anton-Culver, H. and Jablons, D.M. (2007) Natural History of Stage I Non-Small Cell Lung Cancer: Implications for Early Detection. Chest Journal, 132, 193-199. http://dx.doi.org/10.1378/chest.06-3096

[16] Landreneau, J.P., Schuchert, M.J., Weyant, R., Abbas, G., Wizorek, J.J., Awais, O., et al. (2014) Anatomic Segmentectomy and Brachytherapy Mesh Implantation for Clinical Stage I Non-Small Cell Lung Cancer. Surgery, 155, 340346. http://dx.doi.org/10.1016/j.surg.2013.06.055

[17] Howington, J.A., Blum, M.G., Chang, A.C., Balekian, A.A. and Murthy, S.C. (2013) Treatment of Stage I and Stage II Non-Small Cell Lung Cancer. Diagnosis and Management of Lung Cancer, 3rd ed: American College of Chest Physicians Evidence-Based Clinical Practice Guidelines. Chest, 143, 278-313. 
[18] Wolf, F.J., Grand, D.J., Machan, J.T., DiPetrillo, T.A., Mayo-Smith, W.W. and Dupuy, D.E. (2008) Microwave Ablation of Lung Malignancies: Effectiveness, CT Findings, and Safety in 50 Patients. Radiology, 247, 871-879. http://dx.doi.org/10.1148/radiol.2473070996

[19] Deslauriers, J. (2012) Mediastinal Lymph Node Metastases: Ignore? Sample? Dissect? The Role of Mediastinal Node Dissection in the Surgical Management of Primary Lung Cancer. General Thoracic and Cardiovascular Surgery, 60, 724-734. http://dx.doi.org/10.1007/s11748-012-0086-3 
Scientific Research Publishing (SCIRP) is one of the largest Open Access journal publishers. It is currently publishing more than 200 open access, online, peer-reviewed journals covering a wide range of academic disciplines. SCIRP serves the worldwide academic communities and contributes to the progress and application of science with its publication.

Other selected journals from SCIRP are listed as below. Submit your manuscript to us via either submit@scirp.org or Online Submission Portal.
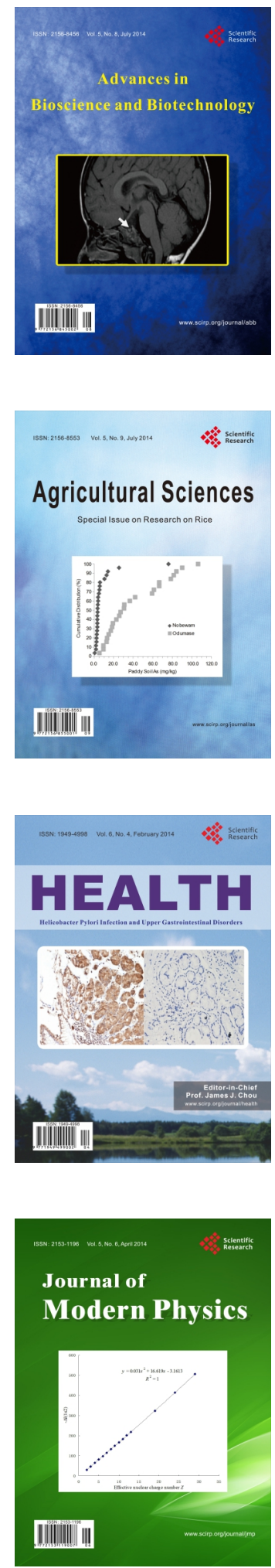
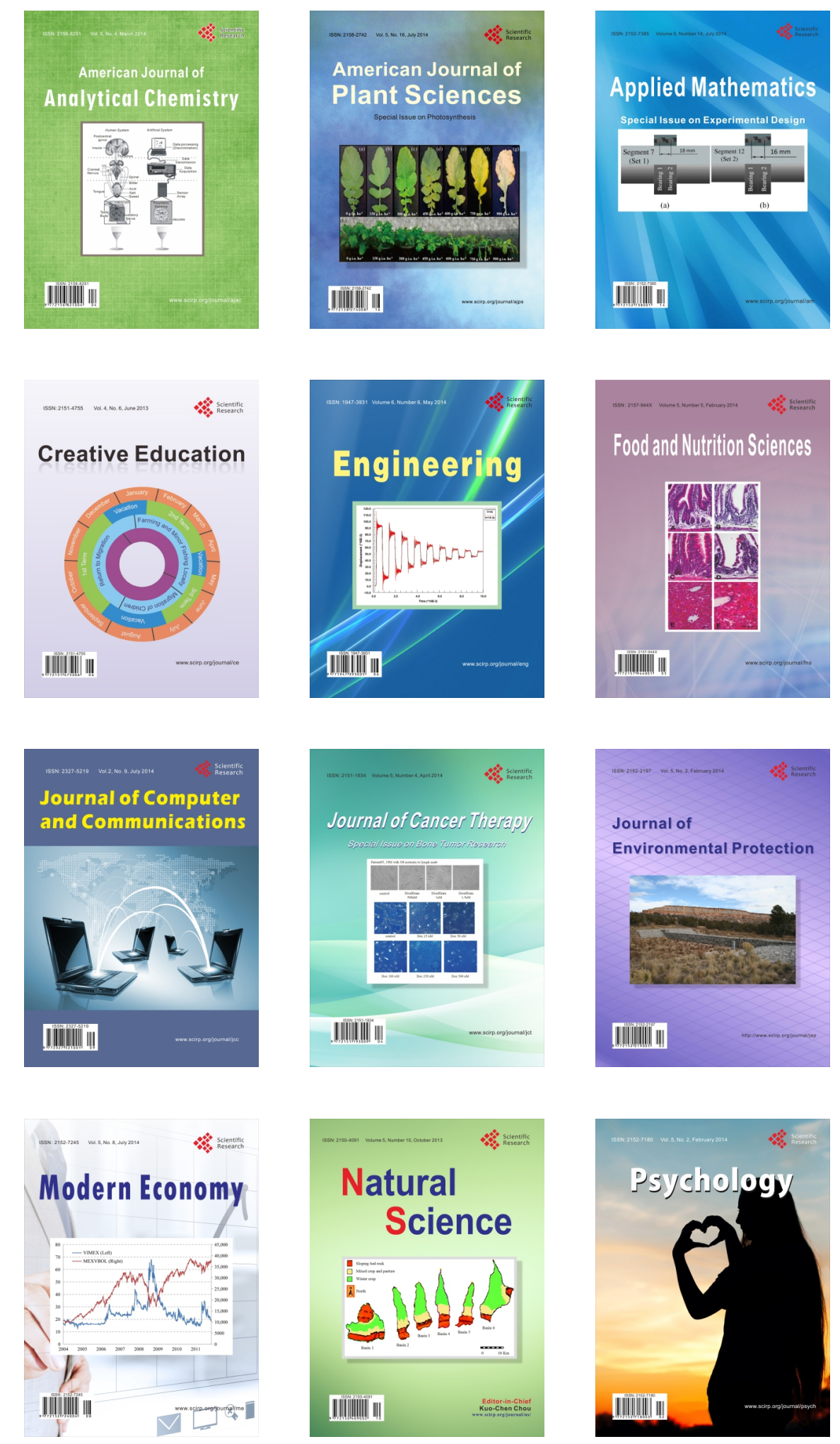